\title{
Dietary determinant of severe acute malnutrition among infants: Evidence from a case controlled study at a Central Indian district
}

\author{
Pavan Pandey ${ }^{1}$, Shivendra Kumar Singh ${ }^{2}$
}

${ }^{1}$ Public Health Specialist, Program Office, Jhpiego India. ${ }^{2}$ Professor, Department of Community Medicine and Public Health, King George's Medical University, Lucknow, UP, India.

\begin{abstract}
Breast feeding and complementary feeding practices ultimately determine the nutritional status of newborn at the end of infancy. The objective of the present study was to find the possible causes of malnutrition in context of breastfeeding and complementary feeding practices adopted by families of infants aged 6-12 month old. A community -based, unmatched, case-controlled study was conducted involving 78 cases and 156 controls in the Raisen district of Madhya Pradesh, India. The study included infants aged 6- 12 months who were enrolled in the Integrated Child Development Scheme. Cases and controls were selected through a multi-staged sampling strategy. Cases were those with severe acute malnutrition and controls were those with no malnutrition as per the World Health Organization criteria. Data related to the breastfeeding, pre-lacteal feeding and complementary feeding practices were collected using a pre-tested questionnaire. Descriptive and bivariate analyses were carried out. $P$-value and Odds ratios were calculated. The proportion of exclusive breastfeeding among cases and control was $10.3 \%$ and $24.4 \%$ respectively. The high odds of malnutrition were related to lack of exclusively breastfeeding [COR $(95 \% \mathrm{CI})=4.69(2.50-6.53)]$, lack of feeding semisolid food, less frequent complementary feedings [COR(95\% CI $)=5.69(3.01-8.93)]$, lack of hand washing by caregivers $[\operatorname{COR}(95 \% \mathrm{CI})=2.44(1.10-3.19)]$, and lack of use of disinfected drinking water for infants. Proper health education should be imparted not only to mothers but also other family members involved in the child's care.
\end{abstract}

Keywords: Severe acute malnutrition, infant, breastfeeding, complementary feeding, India.

\section{Introduction}

The period from birth to two years of age has been recognized as a critical window for proper physical and mental development of children, in order for them to reach their full potential. ${ }^{1}$ The achievement of these developmental goals may be hindered during the first two years of life due to increased incidence of growth faltering, deficiencies of certain micronutrients, and common childhood illnesses such as diarrhea. ${ }^{1-3}$ It has been scientific proven that, it is very difficult to reverse the stunting that has occurred during the first two years of life. ${ }^{1}$

Breast milk by itself is sufficient for complete physical and mental development of infant up to 6 months of life. ${ }^{4}$ Therefore UNICEF, WHO and the government of India, all recommends that each mother practice Exclusive Breast Feeding (EBF) for the first six months of life. ${ }^{5,6}$ The risk of mortality and morbidity due to diarrhea and other infections is higher among infants who are not exclusively breastfed. ${ }^{7,8}$. Complementary feeding is defined as the process of giving external food to infant from 6 months onwards when breast milk alone is no longer sufficient to meet the nutritional requirements of the infant. ${ }^{9,10}$ The quality, consistency and content of the food introduced as part of the complementary feeding are very crucial to the child's development. ${ }^{9}$ If the complementary food is contaminated, has low energy density or low nutritive value, then it can result in poor nutritional status and sub-normal development of the infant. ${ }^{10}$

The method/manner in which a child is fed also plays a

\section{Practice Points}

- Proper breastfeeding and appropriate complementary feeding practices significantly influences the nutritional status of an infant and his/her future potential.

- Most common type of pre-lacteal feed given was honey (34.\%) followed by animal milk $(32.1 \%)$.

- Only $10.3 \%$ of cases were exclusively breastfed compared to $24.4 \%$ controls. The most common reason for non-exclusive breastfeeding was that mothers were not available all the time/they were at work $(41.4 \%)$.

- The decision on the age of starting and content of complementary feeding was most commonly taken by infant's mother. Factors which increased the odds of severe malnourishment were lack of diet diversity, less frequent feeding, no hand washing before feeding, lack of separate vessel for infant and feeding nonsemisolid food.

- Proper health education should be given not only to mothers but also the family members and should start from the antenatal period and must be continued up to the end of infancy period.

Correspondence: Dr. Pavan Pandey Public Health Specialist, House No. E- 33, Surya Apartments, Model Town Bhilai, Durg Chhattisgarh 490020, India. Email: dnameispaone@gmail.com. 
role in the development of the infant. It is recommended that parents/caretakers practice 'responsive feeding', i.e., by applying the principles of psycho-social care while feeding children.

According to the National Family Health Survey-3 (NFHS), the prevalence of Severe Acute Malnutrition (SAM) in infants aged 6-11 months was $15.3 \%$ and $20.2 \%$ in India and Madhya Pradesh, respectively. ${ }^{11,12}$ The prevalence of exclusive breastfeeding in Madhya Pradesh increased from $14.9 \%$ in 2005 to $34.5 \%$ in $2015 .{ }^{13}$ Overall in India, only $21 \%$ of children age $6-23$ months are fed according to all three practices of Infant and Young Child Feeding (IYCF) guidelines. ${ }^{11}$ In Madhya Pradesh, the proportion of infants who are fed correctly based on the three recommendations of IYCF is merely $8.1 \%$ and $13.1 \%$ in the age groups $6-8$ and 911 months, respectively. ${ }^{12}$

The nutritional status of infants aged 6-12 month is mainly determined by the breastfeeding and complementary feeding practices that are prevalent in a particular community/society. ${ }^{14,15}$ These practices in turn are influenced by the nature of the family, urban/ rural locality, knowledge on breastfeeding and complementary feeding, education status of the parents, place of delivery, antenatal care (ANC) visits, customs (such as giving pre-lacteal feed), and beliefs. ${ }^{16-19}$ In today's world, new factors are increasingly becoming important such as increasing numbers of women being employed outside the home, increasing advertisement of baby food etc. 16,20 High rates of severe acute malnutrition among infants are definitely linked to the poor breastfeeding and complementary feeding practices followed in a given community. ${ }^{21}$ Many previous studies have explored breastfeeding and complementary feeding practices prevailing in communities, but only a very few have studied these practices exclusively in relation to severe acute malnutrition in infants. In the present study, the risk factors for severe acute malnutrition among infants were examined in the context of breastfeeding and complementary feeding practices which are followed by families in Raisen district of India.

\section{Materials and methods}

Study design: This was a community-based, unmatched case-controlled study.

Setting: The present study is a part of a larger study to assess the overall demographic, social, dietary, living conditions and economic characteristics of families with one or more children with severe acute malnutrition.

Study location: The present study was conducted in the rural and urban areas of district Raisen, Madhya Pradesh, Central India.

Study Duration: The study was conducted over five months (July-November 2015). The duration of data collection was three months (August-October 2015).

Study Participants: All the children between 6-12 months of age that were enrolled in the Integrated Child Development Scheme (ICDS) of the district Raisen.

Source of participants: Under the ICDS scheme, there is an Aganwadi Centre (AWC-courtyard) located appropriately to cover a population of 800-1000, which is managed by an Aganwadi worker (AWW- grass root worker of ICDS scheme). ${ }^{22}$ Each AWW worker records anthropometric measurements of all children enrolled in her center and sends it to the Child Development Project Officer (CDPO) posted at each block of the district on a monthly basis, who in turn sends it to higher authorities.

Case definition: Severe acute malnutrition among infants of 6-12 months of age was defined as per the WHO guidelines i.e., infants with mid upper arm circumference $<11.5 \mathrm{~cm}$ or infants who weigh $<(-) 3$ standard deviations (SD) for height as per WHO anthropometric guidelines, or both. ${ }^{23}$

Inclusion Criteria for cases: (i) Infants with severe acute malnutrition whose parents gave valid informed consent for the study.

Exclusion criteria: (i) Infants with severe acute malnutrition whose parent did not give consent for the study. (ii) Infants diagnosed with chronic illnesses including tuberculosis, HIV, renal disease, cardiac diseases and congenital abnormalities. (iii) Infants whose mother died any time after giving birth. (iv) Infants with mothers who had contraindications for breastfeeding.

Control definition: infant with $>(-) 2$ SD weight for height and belonging to same gender and having same age in months as case. Inclusion criteria for controls: (i) Infant belonging to a different family from the case. (ii) Infant enrolled in the ICDS scheme. (iii) Infants whose parents gave valid informed consent for study.

Sampling: The study employed a multistage sampling strategy. The ICDS scheme has divided the Raisen districts into 7 developmental blocks, each headed by a CDPO. ${ }^{24}$ In the first stage, three blocks were chosen by simple random sampling. In the second stage, all the children with severe acute malnutrition in the age group 6-12 months belonging to all AWCs of the selected blocks were enrolled. In the third and final stage, all the children from every AWC in a selected block who fulfilled our inclusion criteria were enrolled in our study. The controls were taken from the same AWCs as cases. If we could not find the control from an AWC to match a case, then controls from the nearest AWC were selected.

Selection of participants: Monthly progress reports (MPR) for every month from every block is generated by CDPO, and it includes the number, age group and gender of all children with SAM in a given block. From the CDPO's office, a list of names and address of AWC to which all children with SAM (cases) belongs, and name and phone number of the AWW was noted. After reaching a particular AWC, the identity of a case was verified and thereafter anthropometric measurements of the case were measured after obtaining permission from the AWW. Anthropometric measurements of the infant were taken according to the WHO standardized techniques. ${ }^{23}$ Anthropometric measurements were taken by the researchers themselves. Children were also assessed for the presence or absence of edema of the feet. Anthropometric measurements of children were taken at the aganwadi centre. After confirming that the child is severely malnourished as per the WHO's

South East Asia Journal of Public Health 2016;6(1):32-39 
classification, parents of cases were informed about the purpose and nature of the study. Thereafter, valid informed consent was obtained from the parents of each case. The same procedure was adopted for selecting controls. Two controls were selected per case.

Sample size: All the infants enrolled in ICDS from the selected three blocks of district Raisen fulfilling the inclusion criteria during the period of data collection were enrolled in the study. Following this we approached a total of 87 cases and 169 controls.

Data collection: A questionnaire was designed after a literature search on breastfeeding and complementary feeding guidelines as advised by WHO, UNICEF and the government of India. ${ }^{5,9,10,25}$ The questionnaire was translated from English to the local language by a translator, and the responses were translated back to English. The questionnaire was pretested on mothers of 15 children with severe malnutrition admitted to the nutritional rehabilitation center at community health centre Mandeep, district Raisen; after that necessary modifications were done. Results of pre-testing were excluded from final analysis. The final version of the questionnaire had a reliability of $\alpha=0.92$ on field testing.

Diet Survey: the data about complementary feeding practices was obtained using a 24 -hour recall method. ${ }^{26}$

Variables: A questionnaire was used to collect data on all aspects of breastfeeding (frequency, duration, pre-lacteal feeding) and complementary feeding (age of starting, frequency, the variety of foods, mode of feeding). Minimum dietary diversity was defined as the proportion of children who were fed foods from 4 or more food items out of the seven major foods items within 24 hours preceding the survey. 25 The questionnaire was administrated to mothers of cases and controls at their respective house. Hand washing: For the purpose of study we defined 'hand washing' as washing hands with soap or detergents using any methodology for any duration of time. Hand washing with just plain water without using soap or detergents was not considered as hand washing.

Outcome variable: The outcome variable was the duration of feeding only breast milk to infant, practices of exclusive breastfeeding and adoption of standard complementary feeding practices by families of cases and controls.

Potential confounding variable: An important confounder was the per-capita income of families of cases and controls, as there are chances that those families of controls which have higher per-capita income are likely to spend more on the child's nutrition and diet. We minimized the effect of this confounder variable by selecting controls from such families who had the same type of ration card as families of cases. Wherever possible, the facts stated by the respondent in the interview were cross-checked by the data collector such consistency of complementary food, vessel/ container of feeding, the variety of food served to cases and controls.

Data Analysis: Data were checked for completeness, and then were finally entered into SPSS version 20.0 software. Anthropometric data were calculated by using WHO anthro2010 software and WHZ-scores were also being generated based on the WHO child growth standards. Descriptive statistics were used to describe the sample. The results of the descriptive statistics were expressed as a percentage and frequency, as well as discordant and concordant pairs were described. A $p$-value below 0.05 was considered statistically significant. A bivariate analysis was performed on the independent variables and their proportions and crude odds ratio were computed against the outcome variable to identify the factors that are associated with severe acute child malnutrition. This study, involving infant and mother enrolled in the ICDS scheme was conducted after receiving ethical clearance from institute ethical board. Written informed consent was obtained from parents of cases and controls. Confidentiality of the information given by the respondents was maintained throughout the study. During data collection, if any infant whether cases or controls needed any medical attention, they were referred to the health facilities for proper treatment.

\section{Results}

For the present study we approached a total of 87 cases and 169 controls. Of the 87 cases, mothers of 5 cases refused to participate in study and 4 were excluded using inclusion/exclusion criteria. Of the 169 controls we approached, mothers of 9 controls refused to constant for study and mothers of 4 controls were not available for interview. Thus final analysis was done on a total of 78 cases and 156 controls.

The demographic characteristic of families of cases and controls are presented in Table 1 . Most of the mothers of both cases and controls were 20-25 years old. Most of the cases were 8-9 months of age. Birth order of most of the cases was third or higher. The proportion of males and females among cases was $44.9 \%$ and $55.1 \%$, respectively. The breastfeeding practices followed by the mothers of both cases and controls are presented in Table 2. The delay in initiating breastfeeding beyond the stipulated time was more common after caesarean sections as compared to vaginal deliveries. The prevalence of pre -lacteal feed was higher (close to $70 \%$ ) among those children who were born by caesarean sections (data not shown). Among cases, the most common reason for pre-lacteal feedings was pressure from relatives $(45.3 \%)$ followed by traditional customs $(34.0 \%)$. On being asked the type of pre-lacteal feed given, the most common answer was honey $(34.0 \%)$ followed by animal milk (32.1\%). Only $10.3 \%$ of cases were exclusively breastfed compared to $24.4 \%$ controls. A considerable proportion of cases $(23.1 \%)$ were given breast milk only until 3 months of age, against the recommended 6 months. This was also reflected by the poor knowledge of mothers regarding exclusively breastfeeding.

Among mothers of cases, a large proportion (39.7\%) believed that the right age for starting giving water to infants was 4 months. The most common reason cited by mothers or starting external food before 6 months of age was that they were not available all the time/ they had to work $(41.4 \%)$. On being probed about the type of first external food given to the infant, the most common reply was animal milk $(35.7 \%)$ followed by the mixture of pulses and rice (17.1\%). 
Pandey \& Singh $\mathbf{~ D e t e r m i n a n t s ~ o f ~ s e v e r e ~ m a l n u t r i t i o n ~ a m o n g ~ i n f a n t s ~ i n ~ I n d i a ~}$

Table 1: Distribution of study participants by socio-demographic profile

\begin{tabular}{|c|c|c|}
\hline Demographic Characteristics & $\begin{array}{c}\text { Cases }(n=78) \\
n(\%)\end{array}$ & $\begin{array}{c}\text { Controls }(\mathrm{n}=156) \\
\text { n }(\%)\end{array}$ \\
\hline \multicolumn{3}{|l|}{ Age of mother (in years) } \\
\hline$<20$ & $19(24.4 \%)$ & $12(7.7 \%)$ \\
\hline $20-<25$ & $33(42.3 \%)$ & $79(50.6 \%)$ \\
\hline $25-<30$ & $19(24.4 \%)$ & $45(28.8 \%)$ \\
\hline 30 and above & $7(9 \%)$ & $20(12.8 \%)$ \\
\hline \multicolumn{3}{|l|}{ Educational qualification of mother } \\
\hline Illiterate & $28(35.9 \%)$ & $38(24.4 \%)$ \\
\hline Up to Primary & $19(24.4 \%)$ & $47(30.1 \%)$ \\
\hline Up to High School & $18(23.1 \%)$ & $34(21.8 \%)$ \\
\hline Intermediate and above & $13(16.7 \%)$ & $37(23.7 \%)$ \\
\hline \multicolumn{3}{|l|}{ Occupation of mother } \\
\hline House wife & $23(29.5 \%)$ & $23(14.7 \%)$ \\
\hline Labourer & $25(32.1 \%)$ & $57(36.5 \%)$ \\
\hline Business & $20(25.6 \%)$ & $42(26.9 \%)$ \\
\hline Service & $10(12.8 \%)$ & $34(21.8 \%)$ \\
\hline \multicolumn{3}{|l|}{ Religion } \\
\hline Hindu & $59(75.6 \%)$ & $109(69.9 \%)$ \\
\hline Muslim & $19(24.4 \%)$ & $47(30.1 \%)$ \\
\hline \multicolumn{3}{|l|}{ Caste (social group) } \\
\hline General & $17(21.8 \%)$ & $39(25 \%)$ \\
\hline Other Backward Class & $20(25.6 \%)$ & $49(31.4 \%)$ \\
\hline Schedule Caste & $19(24.4 \%)$ & $30(19.2 \%)$ \\
\hline Schedule Tribes & $22(28.2 \%)$ & $38(24.4 \%)$ \\
\hline \multicolumn{3}{|l|}{ Type of family } \\
\hline Nuclear & $55(70.5 \%)$ & $103(66 \%)$ \\
\hline Joint & $23(29.5 \%)$ & $53(34 \%)$ \\
\hline \multicolumn{3}{|l|}{ Birth order } \\
\hline 1 & $17(21.8 \%)$ & $48(30.8 \%)$ \\
\hline 2 & $16(20.5 \%)$ & $38(24.4 \%)$ \\
\hline 3 or more & $45(57.7)$ & $70(44.9 \%)$ \\
\hline \multicolumn{3}{|l|}{ Place of delivery } \\
\hline Hospital & $59(75.6 \%)$ & $141(90.4 \%)$ \\
\hline On the way to hospital & $12(15.4 \%)$ & $4(2.6 \%)$ \\
\hline Home & $7(9 \%)$ & $11(7.1 \%)$ \\
\hline \multicolumn{3}{|l|}{ Per capita income per month (in INR*) } \\
\hline$<1000$ & $39(50 \%)$ & $39(25 \%)$ \\
\hline $1000-2000$ & $27(34.6 \%)$ & $51(32.7 \%)$ \\
\hline $2001-5000$ & $10(12.8 \%)$ & $31(19.9 \%)$ \\
\hline 5001 and more & $2(2.6 \%)$ & $35(22.4 \%)$ \\
\hline \multicolumn{3}{|l|}{ Age of infant } \\
\hline $6-<7$ & $4(5.1 \%)$ & $8(5.1 \%)$ \\
\hline $7-<8$ & $4(5.1 \%)$ & $8(5.1 \%)$ \\
\hline $8-<9$ & $11(14.1 \%)$ & $22(14.1 \%)$ \\
\hline $9-<10$ & $17(21.8 \%)$ & $34(21.8 \%)$ \\
\hline $10-<11$ & $22(28.2 \%)$ & $44(28.2 \%)$ \\
\hline $11-<12$ & $20(25.6 \%)$ & $40(25.6 \%)$ \\
\hline \multicolumn{3}{|l|}{ Gender } \\
\hline Male & $35(44.9 \%)$ & $70(44.9 \%)$ \\
\hline Female & $43(55.1 \%)$ & $86(55.1 \%)$ \\
\hline
\end{tabular}

*INR-Indian National Rupee

The complementary feeding practices followed by families/mothers of cases and controls are detailed in Table 3. The data for complementary feeding was obtained using a 24-hour recall method. The decision on the starting age, and content of complementary feeding was most commonly taken by the infant's mother. $26.9 \%$ of cases were given the semisolid food as compared to $55.7 \%$ of controls. Among study participants, only 24.4

South East Asia Journal of Public Health 2016;6(1):32-39
$\%$ of cases and $58.3 \%$ controls were given disinfected water for drinking. Hand washing before feeding infants was followed in families of $29.5 \%$ cases and $57.1 \%$ controls. The diet diversity score was higher among controls as compared to cases.

The bivariate analysis of important factors related to breastfeeding and complementary feeding are 
Table 2: Distribution of study participants as per breast feeding practices by mother

\begin{tabular}{|c|c|c|}
\hline \multirow{2}{*}{ Variables } & Cases $(n=78)$ & Controls $(n=156)$ \\
\hline & n $(\%)$ & $n(\%)$ \\
\hline \multicolumn{3}{|l|}{ Pre-lacteal feeding } \\
\hline Yes & $53(67.9 \%)$ & $75(48.1 \%)$ \\
\hline No & $25(32.1 \%)$ & $81(51.9 \%)$ \\
\hline \multicolumn{3}{|l|}{ Reason for Pre-lacteal feed (Cases $=53$, controls $=75)$} \\
\hline Customs and Belief & $18(34 \%)$ & $27(36 \%)$ \\
\hline Pressure from relatives & $24(45.3 \%)$ & $30(40 \%)$ \\
\hline Mother was not well & $8(15.1 \%)$ & $13(17.3 \%)$ \\
\hline Other & $3(5.7 \%)$ & $5(6.7 \%)$ \\
\hline \multicolumn{3}{|l|}{ Type of Pre-lacteal feeds $($ Cases $=53$, controls $=75)$} \\
\hline Animal Milk & $17(32.1 \%)$ & $19(25.3 \%)$ \\
\hline Holy water & $16(30.2 \%)$ & $25(33.3 \%)$ \\
\hline Honey & $18(34 \%)$ & $30(40 \%)$ \\
\hline Others & $2(3.8 \%)$ & $1(1.3 \%)$ \\
\hline \multicolumn{3}{|l|}{ Colostrum given } \\
\hline Yes & $64(82.1 \%)$ & $108(69.2 \%)$ \\
\hline No & $14(17.9 \%)$ & $48(30.8 \%)$ \\
\hline \multicolumn{3}{|l|}{ Time of starting breast feeding after birth } \\
\hline \multicolumn{3}{|l|}{ After Vaginal Delivery $($ Cases $=62$, controls $=127)$} \\
\hline$<$ one hour & $41(66.1 \%)$ & $97(76.4 \%)$ \\
\hline >one hour & $21(33.9 \%)$ & $30(23.6 \%)$ \\
\hline \multicolumn{3}{|l|}{ After caesarean section (Cases $=16$, controls $=29$ ) } \\
\hline$<4$ hours & $3(18.8 \%)$ & $9(31 \%)$ \\
\hline$>4$ hours & $13(81.2 \%)$ & $20(69 \%)$ \\
\hline \multicolumn{3}{|l|}{ Duration till which only breast milk was fed } \\
\hline$<3$ months & $18(23.1 \%)$ & $9(5.8 \%)$ \\
\hline 3- $<4$ months & $20(25.6 \%)$ & $27(17.3 \%)$ \\
\hline $4-<5$ months & $20(25.6 \%)$ & $43(27.6 \%)$ \\
\hline $5-<6$ month & $12(15.4 \%)$ & $39(25 \%)$ \\
\hline Till 6 completed months & $8(10.3 \%)$ & $38(24.4 \%)$ \\
\hline \multicolumn{3}{|c|}{ Reason for external feeding before 6 months of age (Cases $=70$, controls $=118)$} \\
\hline Had to work/Unavailable all the time & $29(41.4 \%)$ & $47(39.8 \%)$ \\
\hline Child was crying/hungry after breastfeeding & $22(31.4 \%)$ & $34(28.8 \%)$ \\
\hline External food is more nutritious & $11(15.7 \%)$ & $25(21.2 \%)$ \\
\hline Others & $08(11.4 \%)$ & $12(10.2) \%$ \\
\hline \multicolumn{3}{|c|}{ Type of external feeding before six months of age $($ Cases $=70$, controls $=118)$} \\
\hline Animal milk & $25(35.7 \%)$ & $22(18.6 \%)$ \\
\hline Pulses-rice & $12(17.1 \%)$ & $17(14.4 \%)$ \\
\hline Fruits/juices & $8(11.4 \%)$ & $23(19.5 \%)$ \\
\hline Baby food & $7(10 \%)$ & $28(23.7 \%)$ \\
\hline Ghutti (traditional medicine) & $10(14.3 \%)$ & $21(17.8 \%)$ \\
\hline Water & $8(11.4 \%)$ & $7(5.9 \%)$ \\
\hline \multicolumn{3}{|c|}{ Till what age mother thinks breast milk is sufficient for baby } \\
\hline 4 months & $38(48.7 \%)$ & $29(18.6 \%)$ \\
\hline 5 months & $17(21.8 \%)$ & $63(53.4 \%)$ \\
\hline 6 months & $18(23.1 \%)$ & $54(45.8 \%)$ \\
\hline 7 months and more & $5(6.4 \%)$ & $10(6.4 \%)$ \\
\hline \multicolumn{3}{|l|}{ By what age onwards baby should be given water } \\
\hline $3^{\text {rd }}$ month & $5(6.4 \%)$ & $10(6.4 \%)$ \\
\hline $4^{\text {th }}$ month & $31(39.7 \%)$ & $49(31.4 \%)$ \\
\hline $5^{\text {th }}$ month & $27(34.6 \%)$ & $87(55.8 \%)$ \\
\hline $6^{\text {th }}$ month and beyond & $15(19.2 \%)$ & $10(6.4 \%)$ \\
\hline
\end{tabular}

detailed in Table 4. Factors related to breastfeeding which increased the odds of severe malnourishment among infants were lack of exclusive breastfeeding [COR $(95 \% \mathrm{CI})=4.69(2.50-6.53)]$, feeding breast milk only for less than 4 months of age $[\operatorname{COR}(95 \% \mathrm{CI})=8.86(3.13$ 13.64)], and pre-lacteal feeding $[\operatorname{COR}(95 \% \mathrm{CI})=2.25$ (1.11-4.67)]. Factors related to complementary feeding which increased the odds of severe malnourishment were lack of diet diversity $[\mathrm{COR}(95 \% \mathrm{CI})=6.92(3.32-9.48)]$, less frequent feeding $[\mathrm{COR}(95 \% \mathrm{CI})=5.69(3.01-8.93)]$, no hand-washing before feeding $[\operatorname{COR}(95 \% \mathrm{CI})=2.44$
(1.10-3.19)], lack of a separate vessel for the infant $[\mathrm{COR}(95 \% \mathrm{CI})=1.59(1.06-2.43)]$ and feeding nonsemisolid food (liquid + solid ).

\section{Discussion}

Based on the review of the literature, the uniqueness of our study was to assess who has a say in deciding at what age complementary feeding should be started and what should be the contents of complementary feeding. In our study, the odds of

South East Asia Journal of Public Health 2016;6(1):32-39 
Table 3: Distribution of study participants by complementary feeding practices

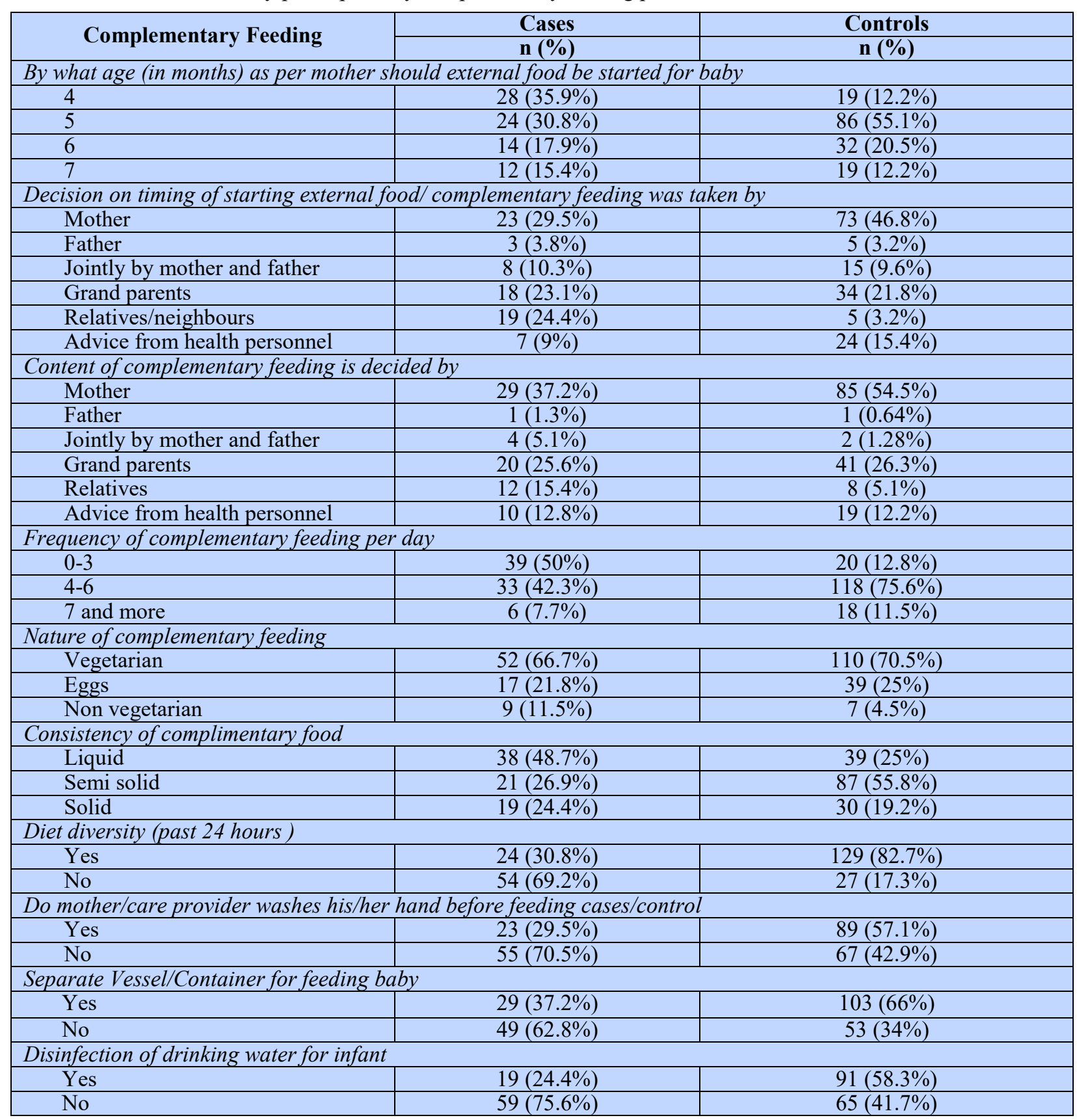

being severely malnourished were related to lack of exclusive breastfeeding, starting external food earlier than 4 months of age, less frequent complementary feeding, not washing hands before feeding the infant and not using disinfected drinking water for the infant.

Infants belonging to families of lower socioeconomic statuses were more likely to be undernourished than their richer counterparts. This finding is comparable to findings of similar studies conducted in many low and middle-income countries and reflects the fact that malnourishment disproportionately affects the poor households. $^{27-29 .} \mathrm{A}$ higher birth order was strongly associated with infant's undernourishment. The prevalence of severe acute under nutrition was higher among infants with higher (3rd or more) birth order. The higher birth order gives less opportunity for exclusive breastfeeding and less attention than an infant normally deserves, thus increasing the risk of malnutrition. ${ }^{28}$ Higher birth order is associated with an increased risk of communicable disease such as diarrhea and pneumonia among infants. ${ }^{29}$

The lack of exclusive breastfeeding and inappropriate complementary feeding practices deprives an infant of essential nutrients during the first year of life. ${ }^{30}$ These practices, if used properly, are known to prevent infective disease by reducing exposure to an infective agent and improving infant's immunity status, thus interrupting the vicious infection-malnutrition cycle. ${ }^{31,32}$ Improving these practices can lead to an improved nutritional status thus improving child survival, growth, and development. This also prevents further episodes of undernutrition in later life. 33,34

\section{Limitations}

The study's findings could be affected by recall bias due to the retrospective collection of data. These problems are inherent in case-control studies. 


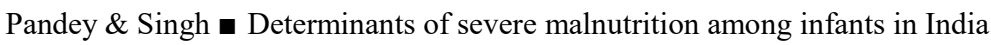

Table 4: Bivariate analysis of selected characteristics of the study participants

\begin{tabular}{|c|c|c|c|c|}
\hline \multirow{2}{*}{ Variable } & Cases & Controls & \multirow[t]{2}{*}{ COR (95\% CI) } & \multirow[t]{2}{*}{$p$-value } \\
\hline & n (\%) & n (\%) & & \\
\hline \multicolumn{5}{|l|}{ Breast Milk } \\
\hline \multicolumn{5}{|c|}{ Exclusive breastfeeding for Six months } \\
\hline No & $70(89.7 \%)$ & $118(75.6 \%)$ & $4.69(2.50-6.53)$ & \multirow[t]{2}{*}{0.003} \\
\hline Yes & $8(10.3 \%)$ & $38(24.4 \%)$ & 1 & \\
\hline \multicolumn{5}{|l|}{ Pre lacteal feed } \\
\hline Yes & $53(67.9 \%)$ & $75(48.1 \%)$ & $2.25(1.11-4.67)$ & \multirow[t]{2}{*}{0.06} \\
\hline No & $25(32.1 \%)$ & $81(51.9 \%)$ & 1 & \\
\hline \multicolumn{5}{|c|}{ Only breast milk feeding till 4 month of age } \\
\hline No & $32(41 \%)$ & $36(23.1 \%)$ & $8.86(3.13-13.64)$ & \multirow[t]{2}{*}{$<0.001$} \\
\hline Yes & $46(59 \%)$ & $120(76.9 \%)$ & 1 & \\
\hline \multicolumn{5}{|l|}{ Complementary feeding } \\
\hline \multicolumn{5}{|l|}{ Dietary diversity } \\
\hline No & $54(69.2 \%)$ & $27(17.3 \%)$ & $6.92(3.32-9.48)$ & \multirow[t]{2}{*}{0.023} \\
\hline Yes & $24(30.8 \%)$ & $129(82.7 \%)$ & 1 & \\
\hline \multicolumn{5}{|c|}{ Separate Vessel/Container for feeding Infant } \\
\hline No & $49(62.8 \%)$ & $53(34 \%)$ & $1.59(1.06,2.43)$ & \multirow[t]{2}{*}{0.041} \\
\hline Yes & $29(37.2 \%)$ & $103(66 \%)$ & 1 & \\
\hline \multicolumn{5}{|l|}{ Frequency of feeding } \\
\hline$<4$ & $39(50 \%)$ & $20(12.8 \%)$ & $5.69(3.01-8.93)$ & \multirow[t]{2}{*}{0.01} \\
\hline 4 and more Closed & $39(50 \%)$ & $136(87.2 \%)$ & 1 & \\
\hline \multicolumn{5}{|c|}{ Hand Washing before feeding Infant } \\
\hline No & $55(70.5 \%)$ & $67(42.9 \%)$ & $2.44(1.10-3.19)$ & \multirow[t]{2}{*}{0.02} \\
\hline Yes & $23(29.9 \%)$ & $89(57.1 \%)$ & 1 & \\
\hline \multicolumn{5}{|c|}{ Consistency of complementary feeding } \\
\hline Liquid & $38(48.7 \%)$ & $39(25 \%)$ & $1.27(0.88,1.77)$ & \multirow[t]{3}{*}{0.05} \\
\hline Solid & $19(24.4 \%)$ & $30(19.2 \%)$ & $1.21(0.90,1.73)$ & \\
\hline Semi solid & $21(26.9 \%)$ & $87(55.8 \%)$ & 1 & \\
\hline \multicolumn{5}{|c|}{ Disinfection of drinking water } \\
\hline No & $59(75.6)$ & $65(41.7 \%)$ & $1.69(1.10,2.09)$ & \multirow[t]{2}{*}{0.027} \\
\hline Yes & $19(24.4)$ & $91(58.3 \%)$ & 1 & \\
\hline
\end{tabular}

\section{Conclusion}

Period from birth to two years of age is a 'critical window' for proper physical and mental development of children. Proper breastfeeding and appropriate complementary feeding practices significantly influences the nutritional status of an infant and his/her future potential. Factors such as duration of exclusively breastfeeding and avoidance of pre-lacteal feeding can be improved by reinforcing health education at every step from the antenatal period onwards. Based on our findings, we recommend health education about right practices of breastfeeding and complementary feeding should be imparted not only for mothers but also to other care givers such as father, grandparents and other household members.

\section{Acknowledgment}

Authors are sincerely thankful to the staff of the district project office Raisen, Madhya Pradesh for their support in carrying out this study. Our sincere thanks to all the families/mothers who had the patience to sit and heedfully discern all our questions and answer them to the best of their abilities. Our prayers lie with the malnourished infants and their families.

\section{Source of funding}

None Received.

\section{Conflict of Interest}

None declared.

South East Asia Journal of Public Health 2016;6(1):32-39

\section{References}

1. Mendez MA, Adair LS. Severity and timing of stunting in the first two years of life affect performance on cognitive tests in late childhood. J Nutr 1999;129(8):1555-62.

2. Black RE, Allen LH, Bhutta ZA, Caulfield LE, de Onis M, Ezzati M, et al. Maternal and child undernutrition: global and regional exposures and health consequences. Lancet 2008;371 (9608):243-60.

3. Victora CG, de Onis M, Hallal PC, Blössner M, Shrimpton R. Worldwide timing of growth faltering: revisiting implications for interventions. Pediatrics 2010;125(3):473-80.

4. Martines JC, Rea M, De Zoysa I. Breast feeding in the first six months: no need for extra fluids. BMJ 1992;304:1068-9.

5. World Health Organization. The optimal duration of exclusive breastfeeding. Report of an Expert Consultation. Geneva: WHO, 2002.

6. Victoria C. Breastfeeding in the 21st century: epidemiology, mechanisms, and lifelong effect. Lancet 2016; 387: 475-90.

7. Quigley MA, Kelly YJ, Sacker A. Breastfeeding and hospitalization for diarrheal and respiratory infection in the United Kingdom Millennium Cohort Study. Pediatrics 2007;119:e837-42.

8. Dadhich JP, Agarwal RK. Mainstreaming early 
and exclusive breastfeeding for improving child survival. Indian J Pediatr 2009;46:11-7.

9. Dewey K. Guiding Principles for Complementary Feeding of the Breastfed Child. Washington, DC: Pan American Health Organization and World Health Organization, 2003.

10. World Health Organization. Complementary feeding of young children in developing countries: a review of current scientific knowledge. Geneva: WHO, 1998.

11. International Institute for Population Sciences and Macro International. National Family Health Survey (NFHS-3), 2005-6, India: Volume I. Mumbai: IIPS, 2007.

12. International Institute for Population Sciences and Macro International. National Family Health Survey (NFHS-3), India, 2005-6, Madhya Pradesh. Mumbai: IIPS, 2007.

13. International Institute for Population Sciences and Macro International. National Family Health Survey (NFHS-4), India, 2015-16: State factsheet - Madhya Pradesh. Mumbai: IIPS, 2016.

14. Kumar D, Goel NK, Mittal PC, Misra P. Influence of infant-feeding practices on nutritional status of under- five children. Indian J Pediatr 2006;73:417-21.

15. Saha KK, Frongillo EA, Alam DS, Ariffen SE, Persson LA, Rasmussen KM. Appropriate infant feeding practices result in better growth of infants and young children in rural Bangladesh. Am J Clin Nutr 2008;87:1852-9.

16. Lauer J, Betran A, Victora C, de Onis M, Barros A: Breastfeeding patterns and exposure to suboptimal breastfeeding among children in developing countries: review and analysis of nationally representative surveys. $B M C \mathrm{Med}$ 2004;2(1):26.

17. Parekh C, Bavdekar S B, Shaharao V. Study of infant feeding practices: factors associated with faulty feeding. J Trop Pediatr 2004; 50:306-8.

18. Jones G, Steketee RW, Black RE, Bhutta ZA, Morris SS. Child Survival Study Group. How many child deaths can we prevent this year? Lancet 2003;362:65- 71.

19. Guldan GS, Fan HC, Ma X, Ni ZZ, Xiang X, Tang MZ. Culturally appropriate nutrition education improves infant feeding and growth in rural Sichuan, China. J Nutr 2000;130(5):120411.

20. Lakati A, Binns C, Stevenson M. The effect of work status on exclusive breastfeeding in Nairobi. A sia-Pacific J Public Health 2002;14(2):85 -90 .

21. Bhutta ZA, Ahmed T, Black RE, Cousens S, Dewey K, Giugliani E, Haider BA, Kirkwood B, Morris SS, Sachdev HP, Shekar M. What works? Interventions for maternal and child undernutrition and survival. Lancet 2008;371 (9610):417-40.
22. Integrated Child Development Scheme. Ministry of women and child development. Government of India. http://icds-wcd.nic.in/icds/icds.aspx (accessed 5th June 2016)

23. World Health Organization. Management of Severe Malnutrition: A Manual for Physicians and Other Senior Health Workers. Geneva: WHO, 2010.

24. Department of women and child development. Government of Madhya Pradesh. ICDS. http:// mpwcdmis.gov.in/Profile/DistrictProfile.aspx (accessed 5th June 2016)

25. World Health Organization. Indicators for assessing infant and young child feeding practices: conclusion of a consensus meeting. Geneva: WHO, 2008.

26. Jackson KA, Byrne NM, Magarey AM, Hills AP. Minimizing random error in dietary intakes assessed by 24 -h recall, in overweight and obese adults. Eur J Clin Nutr 2008;62:537-43

27. Li L, Li S, Ali M, Ushijima H. Feeding practice of infants and their correlates in urban areas of Beijing, China. Pediatr Int 2003;45:400-6.

28. Wamani H, Astrom AN, Peterson S, Tylleskar T, Tumwine JK. Infant and young child feeding in western Uganda: knowledge, practices and socioeconomic correlates. J Trop Pediatr 2005;51:35661.

29. Bantamen G, Belaynew W, Dube J. Assessment of Factors Associated with Malnutrition among Under Five Years Age Children at Machakel Woreda, Northwest Ethiopia: A Case Control Study. J Nutr Food Sci 2014; 4: 256

30. Dewey KG, Brown KH. Update on technical issues concerning complementary feeding of young children in developing countries and implications for intervention programs. Food Nutr Bull 2003;24(1):5-28.

31. Hop LT, Gross R, Giay T, Sastroamidjojo S, Schultink W, Lang NT. Premature complementary feeding is associated with poorer growth of Vietnamese children. $J$ Nutr 2000;130:2683-90.

32. Dewey KG, Cohen RJ, Brown KH, Rivera LL. Age of introduction of complementary foods and growth of term, low-birth-weight, breast-fed infants: a randomized intervention study in Honduras. A m J Clin Nutr 1999;69:679-86.

33. World Health Organization. Global strategy for infant and young child feeding. Geneva: WHO, 2003.

34. WHO Collaborative Study Team on the Role of Breastfeeding on the Prevention of Infant Mortality. Effect of breastfeeding on infant and child mortality due to infectious diseases in less developed countries: a pooled analysis. Lancet 2000;355:451-55. 